\title{
Elements of Relational Contract in the Delivery of Public Infrastructure in Malaysia
}

\author{
Syuhaida Ismail ${ }^{1}$, Aminah Md Yusof ${ }^{2}$ and Wai Soon Han $^{2}$ \\ ${ }^{1}$ University of Technology Malaysia International Campus, Kuala Lumpur, Malaysia \\ ${ }^{2}$ Faculty of Civil Engineering, University of Technology Malaysia, Johor Bahru, Malaysia
}

\begin{abstract}
The involvement of private concessionaire in the delivery of public infrastructure worldwide is apparent in reducing the budgetary burden on the government's part specifically due to the major downturn in the global economy. Their involvement varies from concessionaire, privatization to partnerships. Looking at the most current type of project delivery approach procured around the globe, which is known as Public Private Partnerships (PPP), although the opportunities are widely opened for the private concessionaires to partake in the delivery of public infrastructure projects with numerous incentives by the government, their responses are still minimal. Their reluctance is observed due to the current scenario in the PPP implementation involving the development of monopolies by certain groups of private concessionaires in Malaysia, which consequently reduces the healthy competition among concessionaires. Therefore, this paper is materialized with the aim of determining the elements of relational contract, which can improve the current delivery of public infrastructure project and subsequently eradicate the private concessionaire's lack of enthusiasm. Questionnaire surveys on 22 respondents of construction industry players are undertaken to determine the elements of relational contract suitable to be adopted in public infrastructure delivery in Malaysia in encouraging the involvement of private concessionaires. The results show that relational contract elements of clearly defined scope, integrated project team, mutual alignment of goals and open honest communication should be included in the relational contract elements frameworks due to its potential in overcoming the current recession of private concessionaire's initiatives and ultimately improving the public infrastructure delivery in Malaysia.
\end{abstract}

Keywords: Relational contract, public infrastructure delivery, Public Private Partnership (PPP), Malaysia.

\section{Introduction}

The delivery of infrastructure is imperative to support the economic growth of any nation. Takim and Akintoye (2002) suggest that the pace of the economic growth of any nation can be measured by the development of physical infrastructures, such as buildings, roads and bridges. In this sense, considering the toll roads in Malaysia as an example, a
$1800 \mathrm{~km}$ of toll roads which have been either constructed or over which concession agreements have been signed with private concessionaire over the last two decades (Ward and Sussman, 2005) play a major role towards a sustainable urbanization of the nation. The delivery of infrastructure, hence, without any doubt, is regarded as a success drive force for the country's economy and social development.

Copyright (C) 2012 Syuhaida Ismail, Aminah Md Yusof and Wai Soon Han. This is an open access article distributed under the Creative Commons Attribution License unported 3.0, which permits unrestricted use, distribution, and reproduction in any medium, provided that original work is properly cited. Contact author: Syuhaida Ismail E-mail: syuhaida@ic.utm.my 
However, there are shortcomings especially concerning the delivery of infrastructure with particular regard to the minimal involvement of concessionaires in its delivery. Therefore, many efforts have been initiated by Malaysia government in encouraging the participation of the private concessionaire in public infrastructure delivery in Malaysia (Syuhaida and Aminah, 2010). Among these efforts is the notable Chapter 10: Streamlining Privatization of Ninth Malaysia Plan (9MP) which emphasizes on increasing the performance of private concessionaire particularly Bumiputera via streamlining the implementation process in terms of its transparency as well as linking the concessionaire's performance to a reward system in boosting their motivation to perform their work efficiently and effectively (Economic Planning Unit, 2006).

The various efforts implemented by the government in ensuring the better involvement of the private concessionaire demonstrate that private concessionaire is a key player in the delivery of public infrastructure projects towards the achievement of the sustainable urbanization. Thus, the obstacles obstructing the private concessionaire's participation in public infrastructure delivery are necessary to be addressed given that the infrastructure has a huge impact on rural development, delivery of better living quality and competitiveness of a country. Furthermore, problems associated with private concessionaire in the delivery of public infrastructure are vital to the development in the light of economy and society of a nation. Failure to tackle the problems will prevent the country from moving towards the high income nation of a sustainable urbanization by the year 2020 simply because the public infrastructure is concerning the society at large (Duffield, 2001).

Looking at the root of cause hindering the private concessionaire's participation, the negative perception among the private concessionaires on the delivery approaches of the public infrastructure projects is observed by this paper as essential to be initially tackled before the streamlining efforts can be successfully implemented. This perception can be diminished by strengthening the delivery approaches via the inclusion of relational contract elements of clearly defined scope, integrated project team, mutual alignment of goals and open honest communication.

Therefore, this paper aim of appraising the knowledge and application of relational contract elements in public infrastructure project delivery in Malaysia is achieved via the paper objectives of reviewing the problems in public infrastructure delivery in Malaysia. This signifies the importance of incorporating the relational contract elements in the current public infrastructure delivery, identifying the relational contract elements procured in construction industry worldwide and developing the framework of relational contract elements consisting of the elements prioritized by the questionnaire survey respondents. These elements have the potential to improvise the involvement of private concessionaires in public infrastructure delivery.

\section{Dilemma of Public Infrastructure Delivery in Malaysia}

In Malaysia, there are various forms of delivery approaches used to deliver public infrastructure, namely Sale of Equity (SOE), Build-Operate-Transfer (BOT), Build-LeaseTransfer (BLT), Build-Operate-Own (BOO) and Land Development (LD). Of these approaches, it is observed by this paper that the most devoted form of approach is Public Private Partnership (PPP). Being all with different branding, all of these approaches share one common character; there is an involvement of private sector embedded throughout its processes. The Malaysian government is seriously seeking to work in partnership with the private sectors for two reasons: the delivery of operational infrastructure in terms of physical building has become a reality with the escalated 
demand of good quality services and facilities by the end-users, as well as money saving strategy further helps to ease the government's budgetary curtailment. Nevertheless, the programme is not without the criticism especially from the taxpayers and therefore, this section discusses the dilemma in public infrastructure delivery with particular respect to those associated with or delivered under the PPP programme.

Herzberg and Wright (2005) disclosed that the main challenge in promoting competiveness PPP is cronyism. As PPP is being popularly implemented in delivering public infrastructure in Malaysia, Malaysia has no exception. A case in point is the delivery of toll roads via PPP which is subject to accusation of cronyism due to lack of transparency in the concessionaire selection process (Ward and Sussman, 2005). This transparency is one of the vital elements of PPP implementation and since it is not being practiced in Malaysia's version of PPP, the transparency status of PPP delivery is questionable by taxpayers whom their money is poured in delivering these PPP projects of public infrastructure.

Apart from that, Ribeiro and Dantas (2007) also highlight that even though Malaysia is observed as one of the most active countries implementing PPP projects in Southeast Asia. PPP in Malaysia, particularly in the delivery of public infrastructure projects, has failed for several reasons. These include high risk investment as the public infrastructure normally involves huge amount of investment, fewer guaranties on the investment return, inaccurately estimated costs and traffic forecasts, overlooked the local conditions as well as low level of confidence to guarantee the long term investment return. In addition, Malaysia has been badly affected by the faulty contracts that contain contingent liabilities, which stand in stark contrast to the development of PPP.

On the other hand, Naidu (2007) also revealed that there is a tendency of financially unsustainable infrastructure projects being eventually taken over by the Malaysia Government. Seremban, Port Dickson Highway and three urban rail transit systems in Kuala Lumpur; namely, Sistem Transit Aliran Ringan (STAR) or Light Rapid Transit System, PUTRA Light Rapid Transit (PUTRA LRT) and KL Monorail system, which generate losses despite profit, are cases in point. In this sense, the tendency and willingness of the Government to take over faulty infrastructure projects will spark serious problem pertaining to the issues of the private sector commitment towards bidding for a project.

Likewise, there are concrete statistics to illustrate that the evaluation process of public infrastructure projects are without rigorous appraisal. Six new hospitals were built, with each costing more than RM 350 million, under the turn-key BOT arrangements between 2003 and 2008 (DAP Economic Bureau, 2009). Nevertheless, the costly new hospitals were subject to serious criticism namely the ICU and surgical unit of Kota Kinabalu's Queen Elizabeth Hospital were shut and three of its blocks were declared unsafe by engineers in October 2008 due to the failure of the concession company to carry out repair and maintenance work although the deteriorating conditions had been reported as early as 2000. Moreover, Subang Jaya Medical Centre (SJMC) was on sale for RM 200 million, which further proved that there is a lack of expertise not only in contractors who built the facility, but also in the management team who manages the medical center.

Having comprehensively discussed the problems that exist in public infrastructure projects in this section, this paper subsequently discusses the possible solution to these dilemmas. It is observed in this paper that the relational contract is able to improve the undertaking practice, and thus is the focus of next section. 


\section{Relational Contract}

Relational contract offers an approach to encourage cost savings and reduction in construction time through systematic contracting procedures (Norlida, 2008). With all the dilemmas in the delivery of public infrastructure and although the projects have been implemented via new and innovative project delivery approaches like PPP, it is observed that relational contract elements embedded in the current delivery approach in the public infrastructure delivery are the best solution to these problems.

Relational contract is defined by Australian Constructors Association (1999) as a contract that is founded on the principle that there is a mutual benefit to the client and the contractor to deliver the project at the lowest cost - when cost increases both the contractor and the client are worse off by relying on commitment, trust, respect, innovation, fairness and enthusiasm. However, Scott (2001), Lendrum (2003) and Nasruddin (2010) simplified this definition by claiming that the relational contract represents the concepts and principles of partnering and supply chain alliancing based on the experience of the relational contract implementation in Europe. This is in contrast with Rahman and Kumaraswamy (2002), who claim that traditional contract is merely a major realignment towards partnering approaches in general. This is because relational contract process initially starts with the project development and definition, or better known as informal alliance, comprising of owner decision to alliance, owner preparatory steps, alliance partner selection and alliance development alignment and commitment; and the latter process is the project execution or labeled as formal alliance (Scott, 2001), which differentiate it from the traditional contract.

Although relational contract is initially designed to overcome the limitation of traditional contract (Junaidah, 2008), synonymous with its time consumption in the development process, cost uncertainties, misalignment between contractual parties etc (Syuhaida et. al, 2011), it opens up the doorway to continuous improvement in performance, communication, trust, risk management and future collaboration (Lim, 2005) for various types of contracts via its core values of the relationship reliance upon commitment, trust, respect, innovation, fairness and enthusiasm (Norlida, 2008). The relational contract element of performance measurement and reward structures is observed by this paper as the main driver of improvising the performance of public infrastructure delivery in Malaysia via PPP, as it is able to recognize and encourage the values-based relationship between contracting parties built upon trust, respect, transparency and open communication (Junaidah, 2008).

Based on the Alan McLennan Strategic Services (2002), the implementation of relational contract elements in traditional contract has confronted various problems embedded in the traditional contract, which is claimed by Rashid (2002) as the most dominant delivery system in Malaysia despite design and build or turnkey. Since these relational contract elements are able to solve the dilemma in traditional contract, it is undoubted that the same elements can be applied to disentangle the current problem rooted from the cronyism practices entrenched in the current public infrastructure projects delivery via PPP. The problems that can be solved via the relational contract elements as quoted from Alan McLennan Strategic Services (2002) and Rousseau (1995) which include self-serving and limited personal involvement in job due to low emotional investment, mindless adherence to traditional outputs, blame culture, "them and us" attitude as well as bureaucratic adversarial processes,

correspondingly via the relational contract elements of customer service view, breakthroughs, learning and creative outcomes, accept responsibilities supportive, learning culture, partnering and cooperative processes for problem solving. 
Looking at how the relational contract elements can be materialized into the current construction projects, this paper reckons the suggestion by Anantaraman (2010) on the relational matters in the international labour standards as one of the streamlining efforts towards its implementation. However, from the four actions proposed: determine the working conditions and terms of employment; regulate relation between employers and workers and regulate relations between the employers or their organizations and workers' organizations; only the last three are accepted by this paper as the proper action to be taken in implementing the relational contract elements in procuring the public infrastructure projects via PPP. In addition, Kumaraswamy et al. (2005) also observe that relational contract could well extend beyond just one project and foster more "sustainable" relationship where the relational contract arrangements enable a client to choose the most competent contractors based on its specific needs and priorities. This consequently minimizes conflicts between interacted employees who have not been working together before, ultimately leading to cost saving in terms of overheads and rework reduction (Kumaraswamy et. al, 2005).

Thus, based on the relational contract elements ability to confront various problems in construction contract and its simplicity of implementation in terms of strengthening the employer-employeeorganisation relationships, it is recognized in this paper that relational contract approach is the alternative approach in contracting. However, there is potential barrier in adopting this approach, which limits its implementation in construction industry particularly in Malaysia for the delivery of public infrastructure projects. Therefore, the succeeding section discusses the relational contract practices in Malaysia in observing the barriers of its implementation.

\section{Relational Contract in Malaysia}

Relationship contracting is still a new paradigm for many construction firms in Malaysia regardless of their scale due to the lack of promotion in terms of its usage by the Public Works Department (PWD) and Construction Industry Development Board (CIDB) (Lim, 2005). Even so, there are still a few projects in Malaysia that adopt relational contract as a part of their procurement route. This includes Amat Group of Companies (ASB), which applies relational contract in their construction projects ranging from building, civil engineering and infrastructure works, restoration and refurbishment work, to road works via its long-term public sector clients, subcontractors and suppliers twelveyear relationship (Bridgett, 2008). On the other hand, MMC-Gamuda Joint Venture Sdn Bhd (MMC-Gamuda JV) also applies relational contract in building the mega tunnel of SMART Tunnel project in order to control floods in Kuala Lumpur.

Nevertheless, the most notable projects that successfully implemented relational contract in Malaysia are Kuala Lumpur International Airport (KLIA) (Lim, 2005) and Petronas Twin Tower, one of the world's tallest building in Malaysia (Junaidah, 2008). As claimed by Rashid (2002), the application of project-based partnering during the construction of KLIA is said to be among the key factors that enable the mega airport project to be completed in record time. As for Petronas Twin Tower, Junaidah (2008) observes that the quality of project and safety of the workforce priorities in the relational contract are a key success of the delivery of Petronas Twin Tower project. This is based on the relational contract principle; when the work, health and safety of the workforce are well taken care of, the employees would have a higher level of confidence, security and ability to perform better. Thus, it is observed by this paper that the readiness of the company to change and 
their willingness to sacrifice money and time in adopting relational contract are paid off with the successful achievement of their projects.

Nevertheless, although vast benefits of implementing relational contract have been thoroughly discussed via various real-time construction projects as well as the practices of construction companies in Malaysia, there are some barriers observed as obstructing the adoption of relational contract in Malaysia. Thus, these barriers need to be revealed before the framework of relational contract elements in public infrastructure project delivery in Malaysia can be adopted in the current delivery of public infrastructure to ensure that PPP can be successfully achieved.

\section{Questionnaire Survey}

A questionnaire survey has been conducted in prioritizing the barriers in implementing relational contract and eventually prioritizing the elements of relational contract to be adopted in the delivery of public infrastructure project, which is initiated with the awareness and acceptance of relational contract in the current practices of construction players in Malaysia. This question is important to ask as it also affects whether or not relational contract is implementable and doable in Malaysia construction industry particularly while delivering public infrastructure projects preferably procured via PPP.

In achieving the aim and objectives of this paper, a quantitative non-experimental research of questionnaire survey has been carried out to develop the framework of the relational contract elements, which is suitable for the delivery of public infrastructure in Malaysia. This questionnaire is developed from the collection of literature reviews on relational contract implemented around the globe where the respondents are required to prioritize the barriers in implementing relational contract in Malaysia as well as the relational contract elements, which they think suitable to be adopted in the delivery of public infrastructure project in Malaysia.

The questionnaire survey is sectioned into four: demographic data of respondents, respondents' awareness of relational contract, potential barriers in implementing relational contract and relational contract elements to be adopted in public infrastructure project delivery in Malaysia. Prior to the questionnaire survey, a pilot survey has been conducted to determine the reliability of the scale and the items in the scale via reliability analysis using the Cronbach's alpha method based on internal consistency (Zaidatun and Mohd. Salleh, 2003) as well as to determine the internal validity in correctly interpreting the relationships between variables (Punch, 2006). The results of the analysis demonstrate that the reliability coefficient is 0.87 , thus are considered reliable to be used as the tool for questionnaire survey.

Based on the objectives of this paper, the simple random sampling (SRS) is adopted by assigning the respondents with a number of each unit of population of construction players involved in the delivery of public infrastructure in Malaysia. From the list of the construction players consisting of public and private sectors involved in the delivery of public infrastructure in Malaysia obtained from Construction Industry Development Board (CIDB), those involved in the public infrastructure delivery of the Ninth Malaysia Plan (9MP) with a total of 22 were approached.

The results of this questionnaire survey are subsequently analysed via Statistical Packages of Social Sciences (SPSS). It is noteworthy to highlight that this questionnaire survey considers the knowledge, understanding, perception and opinion of the respondents of the implementation of relational contract in Malaysia despite the experience solely based on the claim by Syuhaida et. al (2011) that 
relational contract in Malaysia is still at its infancy stage.

\section{Awareness on Relational Contract}

The knowledge and understanding of the respondents on the relational contract implementation in Malaysia are determined throughout Section C: Knowledge and Understanding on Relational Contract of the questionnaire survey form. This section is pivotal in determining the awareness of construction players on the existence and eventually the implementation of relational contract in supporting the claim on the infancy of relational contract in Malaysia. The results demonstrate that the majority of the respondents amounting to 77 percents are not aware of the existence of relational contract in the construction industry. This is due to the fact that there is a deficient effort by PWD and CIDB as claimed by Lim (2005) in encouraging the adoption of relational contract within the construction projects in Malaysia. Besides, the residual of 23 percent does not have a direct experience in implementing this contract although they have the knowledge on relational contract. The knowledge is obtained from secondary sources or experiences of counterparts involved in the delivery of relational contract. Nevertheless, based on this knowledge, the respondents input on the potential barriers in adopting relational contract in Malaysia is assessed as discussed in the succeeding section.

\section{Potential Barriers on Relational Contract Implementation}

From the literature review, it is observed in this paper that there are five potential barriers which are most dominant in obstructing the growth of the relational contract in Malaysia construction objectives: lack of client knowledge project processes and relational contract, lack of trust between contracting parties, failure to share information between contracting parties, persistence of "master" (i.e. client/prime consultant) and "slave" concept as well as unfair risk-reward plan. Thus, the respondents were asked about these five potential barriers for them to prioritize which barriers they think are the most potentially significant in obstructing the construction players in Malaysia from adopting relational contract based on their personal experience, knowledge, judgment and opinion.

Lack of client knowledge about project processes and relational contract (C1) is rated as the most potential barrier in implementing relational contract in Malaysia because respondents agree that knowledge of the relational contract concepts and principles is important before this contract can be successfully applied. Both client and contractor must understand how the contract works, such as the content of the contract and the project process in order to ensure the effectiveness of this contract. On the other hand, this paper also observes that the minimal awareness of the respondents on the relational contract also reflects the respondents' prioritization of $\mathrm{C} 1$ as the most potential barrier.

The second barrier, persistence of "master" (i.e. client/prime consultant) and "slave" concept (C4) is observed in this paper as not really occurring in Malaysia construction industry as contracting parties in the industry usually have a good relationship among them. The high agreement recorded is probably due to the respondents who do not fully understand the terms of "master" and "slave" concept in the relational contract implementation in Malaysia.

Unfair risk-reward plan (C5) is also observed by this paper as not a potential barrier in the construction industry, as all contracting parties are aware of their role and scope of work as well as the portion of risk and reward that they should bear in the project. Failure to share information between contracting parties (C3) is also considered not being a barrier in adopting relational contract as in the practice of traditional contract, the most usable type of contract in 
Malaysia (Rashid, 2002), sharing information is not a problem as the contracting parties realize that cooperation is paramount in achieving the mutual project goal. Lastly, having conferred lack of trust between contracting parties (C2), since the contracting parties are willing to share information in traditional contract, they would not face much difficulty in accepting the 'open book' concept in relational contract as certain level of trust has been established between them. Therefore, it can be concluded that the only potential barrier in adopting relational contract is the lack of client knowledge because relational contract may not be adopted if the client himself does not understand the fundamentals of relational contract.

Therefore, seeing lack of client knowledge about project processes and relational contract (C1) as the most of the potential barriers obstructing the adoption of relational contract in Malaysia which is foreseen as can be successfully encountered, this paper observes that there is a huge potential for the relational contract elements to be incorporated in the public infrastructure delivery particularly via PPP. Hence, the subsequent section confers the results of the questionnaire survey on the relational contract elements that are suitably adopted in Malaysia public infrastructure delivery.

\section{Relational Contract Elements in Public Infrastructure Delivery}

Despite the potential barriers, the questionnaire survey also assesses the elements of relational contract to be embedded in the public infrastructure delivery in Malaysia, which is functioned in achieving the main aim of this paper. The results illustrate that the most preferable relational element to be added in the current delivery of public infrastructure in Malaysia is clearly defined scope (D3). This is unquestionable, as via a clearly defined scope, every level in the organisation will have a better understanding among each other in permitting cooperation of work in achieving mutual goals (Nurul Alifah, 2007). Therefore, in improvising the implementation of PPP in Malaysia in providing the public infrastructure, this element needs to be added so that the industry players understand that having individual goals rather than organizational goals does not assist the construction industry in upgrading its quality or ensuring the success of the project.

The second preferred element of relational contract in the delivery of public infrastructure is integrated project team (D5) where integrated project team rather than an individual project team is paramount in achieving the mutual goal of the project. Thus, the integration is crucial in traditional contract in improving its current implementation in construction industry. As for the third rated element, alignment of goal is important as every party involved should have the same goal. In contrast, individual goals lead to merely one party achievement and this apparently will not guarantee the success of the project. Besides, an open honest communication is also vital to create trust among the contractual parties.

Other elements, alignment of goals (D1), risk allocation (D2), form of contract (D4), gain share/pain share (D6) and open honest communication/behavior/change of attitude (D7), which are lower-rated, are observed in this paper as not significant in influencing the improvement of public infrastructure delivery. The type of contract is observed as not an issue since all contracting parties are aware of the terms and conditions of each contract upon which they have agreed on entering the contract. The last element of gain share and pain share is also not an element to be added as the risk and reward has been stated in the contract and there is no way for the contracting parties to share other parties' pain. Most of the respondents of this questionnaire survey are comfortable with the current nature and prefer it to be maintained. 
Nevertheless, this paper disagrees with the exclusion of risk allocation relational contract element from the public infrastructure delivery. Although it is lowrated by the respondents as an element not to be added in the better delivery of public infrastructure project, this paper observes that risk allocation is one of the vital elements of PPP which must be transparently made known to the public whom their taxes and money have been poured into kickstarting the delivery of public infrastructure in Malaysia. On the other hand, the risk allocation is important as it plays a major role in encouraging the participation of private companies to partake in the public infrastructure project delivery. This is in line with Syuhaida (2009) who claims that fair allocation of risk to the party best able to bear the risks will be able to attract the private concessionaire's participation despite the loan assistances by the government in involving themselves in the delivery of public infrastructure in Malaysia.

From the analysis, it can be concluded that it is important to define project goals and project scopes in a complete and unambiguous manner. It is important to have an Integrated Project Team in achieving the project goals which operate on mutual trust by putting the best interest of the project ahead of purely self-centered gains, achieving a single and unified team (Australian Constructors Association, 1999). In addition, alignment of goal is vital in facilitating an effective teamwork and communication. In order to encourage the contractual parties to confront issues and differences from the perspective of developing solutions rather than allowing them to enter into disputes, open honest communication is highly recommended to be added into the current delivery of public infrastructure via PPP in Malaysia.

Thus, it is apparent that there is a huge potential for relational contract elements to be adopted in the delivery of public infrastructure project in Malaysia. Therefore, it is no doubt that this framework of the relational contract elements, which is specifically suitable for the delivery of public infrastructure in Malaysia, will play a significant role in improvising the current public infrastructure in Malaysia which are obnoxious with various problems of cost and time overruns as well as poorly constructed facilities, rooted from the cronyism practices entrenched in the current public infrastructure projects delivery via PPP.

\section{Conclusion}

The aim and objectives of this paper have been materialized dealing with the problems disentangling the public infrastructure delivery in Malaysia of minimal participation of private company venturing into public projects due to lack of confidence; government's budgetary curtailment; cronyism practices embedded in PPP; nontransparency in the public infrastructure project procurement in terms of risk allocation, guarantees on the investment return, cost estimation costs and traffic forecasts; as well as the unsustainable public infrastructure, can be overcome and eventually can be improvised by adopting the elements of relational contract of clearly defined scope between contracting parties, adoption of integrated project team in contracting, alignment of goals among contracting parties and an honest communication. Nevertheless, despite the significant establishment of relational contract elements in public infrastructure delivery in Malaysia, there are some limitations borne whereby if these can be eliminated or at least be reduced, the relational contract elements shall have a brighter potential to be implemented for any kind of project delivery in Malaysia. These include the lack of promotion on the relational contract implementation in Malaysia, which consequently leads to the lack of awareness of the relational contract existence among the construction players.

Yet, there is still a huge potential for this framework to be doable in Malaysia's construction industry, particularly in the 
public infrastructure delivery. Future studies on the framework in the relational contract implementation in Malaysia, which clearly identify the conceptual and theoretical, procedures and stakeholders involved, are expected to be developed. Besides, it is forecasted that research on integrating the relational contract elements into other types of procurement namely design and build, Turnkey etc., will be undertaken following the findings of this paper. Therefore, since substantial information on the concept of relational contract and the potential of its application in Malaysia have been provided, it is hoped that this paper would open up the door to further introduction and promotion of relational contract in Malaysia.

\section{Acknowledgement}

The author would like to thank Ministry of Higher Education, Universiti Teknologi Malaysia (UTM), Research Management Centre (RMC) and Innovative Construction (ICON) Research Alliance for their financial assistance under the Research University Grant (GUP) 00H47 and Short-Term Research Grant 77332.

\section{References}

Alan McLennan Strategic Services (2002). "Relationship in Project Delivery," Hamilton Island: Civil Contractors Federation 2002 Annual Conference.

Anantaraman, V. (2010). "Malaysian Industrial Relations System: It's Congruence with the International Labor Code A Background Paper on the Seminar," Persidangan Perwakilan MTUC. 28-29 Dec 2010. Petaling Jaya, Selangor.

Australian Constructors Association (ACA) (1999). "Relationship Contracting: Optimising Project Outcome," North Sydney: ACA.

Ashcraft, H. W. (2008). "Building Information Modeling: A Framework for Collaboration," San Francisco, CA: Construction Lawyer.
DAP Economic Bureau (2009). Democratising Malaysia's Economy: Budget Strategies for Economic Transformation, Democratic Action Party, Chapter 9, pp. 84-85.

Duffield, C. F. (2001). 'An Evaluation Framework for Privately Funded Infrastructure projects in Australia,' Unpublished PhD thesis. Engineering Project Management Group, Department of Civil and Environmental Engineering, the University of Melbourne, Victoria, Australia.

Economic Planning Unit (EPU) (2006). 'Ninth Malaysia Plan 2006-2010,' Putrajaya, Kuala Lumpur: Prime Minister's Department.

Herzberg, B. \& Wright, A. (2005). "Competitiveness Partnerships - Building and Maintaining Public-private Dialogue to Improve the Investment Climate - A Resource Drawn from the Review of 40 Countries' Experiences," Multilateral Investment Guarantee Agency (MIGA).

Junaidah Sulaiman (2008). 'Relational Contracting,' JKR: Complex Project Management Division (PROKOM).

Kumaraswamy, M. M., Rahman, M. M., Ling, F. Y. Y. \& Phng, S. T. (2005). "Reconstructing Cultures for Relational Contracting," Journal of Construction Engineering and Management. Vol. 131, No. 10, October 2005. Pp. 10651075.

Lendrum, T. (2003). The Strategic Partnering Handbook: The Practitioner's Guide to Partnerships and Alliances, 4th Edition. Sydney, Australia: McGraw Hill.

Lim, C. J. (2005). "Relationship Contracting in Malaysia," Unpublished dissertation of Bachelor in Civil Engineering. Australia: University of Southern Queensland.

Naidu, G. (2007). 'Infrastructure Development in Malaysia. International Infrastructure Development in East Asia Towards Balance Regional Development and 
Integration,' ERIA Research Project Report 2007 No. 2.

Nasruddin Faosil (2010). "An Investigation of Relational Contracting Norms in Construction Projects in Malaysia," Unpublished thesis of Doctor of Philosophy. United Kingdom: Loughborough University.

Norlida Kamaluddin (2008). 'Factors Contributing to the Performance of Malaysian International Joint Venture Abroad,' Unpublished thesis. Penang: Universiti Sains Malaysia.

Nurul Alifah, J. (2007). "Relational Contract in Construction Industry in Malaysia," Dissertation of Master in Construction Management. Skudai: Universiti Teknologi Malaysia.

Punch, K. F. (2005). Introduction to Social Research: Quantitative and Qualitative Approaches, Second Edition. London: SAGE Publications Ltd.

Rahman, M. M. \& Kumaraswamy, M. M. (2002). "Joint Risk Management through Transactionally Efficient Realtional Contracting," Journal of Construction Management and Economics. Vol. 20, pp. 4554.

Rashid, K. A. (2002). 'Construction Procurement in Malaysia: Process and Systems, Constrains and Strategies,' Kuala Lumpur: International Islamic University Malaysia.

Ribeiro, K. \& Dantas, A. (2007). "PrivatePublic Partnership in Initiatives around the World: Learning from the Experience," Transportation Research Board.

Rousseau, D. M. (1995). Psychological Contracts in Organisations: Understanding Written and Unwritten Agreements, Newbury Park, CA: SAGE.
Scott, R. (2001). Partnering in Europe: Incentive Based Alliance for Projects, London: Thomas Telford Publishing.

Syuhaida Ismail (2009). "Key Performance Indicators for Private Finance Initiative in Malaysia," Unpublished thesis of Doctor of Philosophy. Skudai, Johor: Universiti Teknologi Malaysia.

Syuhaida Ismail, Aminah Md. Yusof \& Nurul Alifah Jatarona (2011). Improvement of Traditional Contract via Relationship-Based Contract Elements, "International Construction Business and Management Symposium," (ICBMS 2011). September 2122, 2011. Kuala Lumpur: UTM RAZAK School, UTM IC.

Syuhaida Ismail dan Aminah Md. Yusof (2010). Private Finance Initiative (PFI) in Malaysia, the CRIOCM2010 International Symposium on "Advancement of Construction Management and Real Estate". August 6-7, 2010. Thistle Hotel, Johor Bahru: CRIOCM, IMREC, IRDA and UTM.

Takim, R. \& Akintoye, A. (2002). "Performance Indicators for Successful Construction Project Performance," In: Greenwood, D (Ed.), 18th Annual ARCOM Conference, September 2-4, 2002. Vol. 2, pp. 545-55. University of Northumbria: Association of Researchers in Construction Management.

Ward, J. L. \& Sussman, J. M. (2005). “Analysis of the Malaysian Toll Road Public-Private Partnership Program and Recommendations for Policy Improvements," Massachusetts Institute of Technology Engineering Systems Division Working Paper Series. ESD-WP-200509.

Zaidatun Tasir \& Mohd. Salleh Abu (2003). 'Analisis Data Berkomputer SPSS 11.5 for Windows,' Kuala Lumpur: Venton Publishing. 